\title{
Inhibition of Radioiodine Uptake by PBF in Breast Cells is Consistent with Sodium lodide Symporter Repression in the Thyroid
}

UNIVERSITYOF BIRMINGHAM

Poole VL, Read ML, Watkins RJ, Modasia B, Ryan GA, Boelaert K, Franklyn J, Smith VE and McCabe CJ School of Clinical and Experimental Medicine, University of Birmingham, Birmingham, UK.

\section{Background}

Breast cancer is the second most common cancer worldwide and affects 55,000 people in the UK each year. Due the heterogeneity of the disease, breast cancer can be challenging to treat, particularly for patients with triple negative disease.

Radioiodine treatment has been suggested as a potential treatment for breast cancer patients. Although the sodium iodide symporter (NIS) is not expressed in normal breast tissue, it is expressed in $70-80 \%$ of breast cancers. However as in many differentiated thyroid cancers, 131 uptake in breast cancer is limited due to the low levels of NIS located at the plasma membrane

Previous studies in thyroid cells have shown that pituitary tumor-transforming gene (PTTG) binding factor (PBF), is capable of altering the subcellular localisation of NIS and sequestering it in cytoplasmic vesicles (2). This interaction can be abrogated by inhibiting the phosphorylation of PBF a tyrosine residue 174 using the Src inhibitor PP1. Mutants of PBF without this key residue are also unable to bind and sequester NIS

With PBF being upregulated in both thyroid and breast cancer ${ }^{(4)}$, we hypothesised that the interaction between NIS and PBF may also be apparent in breast cancer and that use of PP1 in breast cancer cells may increase radioiodine uptake.

\section{Aims}

(i) To establish whether upregulation of PBF in breast cancer cells can alter the subcellular localisation and functionality of NIS.

(ii) To determine whether the effect of PBF on NIS can be abrogated using the Src inhibitor, PP1, as demonstrated in thyroid cells.

\section{Conclusions}

Taken together these data support the hypothesis that PBF can interact with and alter the subcellular localisation of NIS within breast cancer cells. PBF also decreased radioiodine uptake in breast cancer cells in a similar manner to that demonstrated in thyroid cancer. In vitro radioiodine uptake experiments have shown that radioiodine uptake can be restored using the Src inhibitor, PP1, which prevents phosphorylation of PBF at residue Y174. This suggests that PP1 may have therapeutic benefits and potentially increase uptake of radioiodine in breast cancer patients.

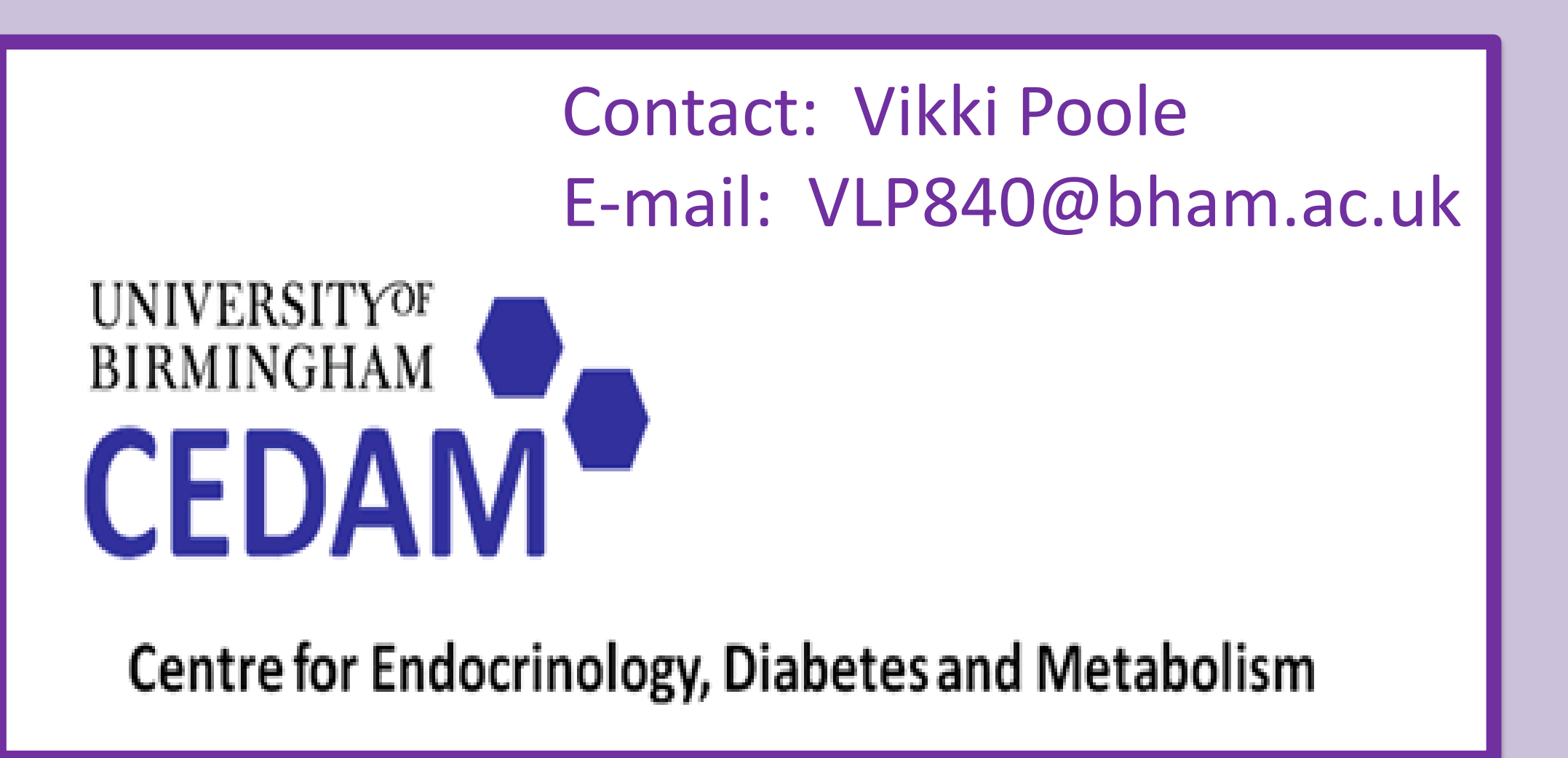

E-mail: VLP840@bham ac.uk 